\title{
Papular elastorrhexis: a rare and benign disease ${ }^{*}$
}

\author{
Layla Comel Corso Perito de Bem ${ }^{1}$, Alessandra Coppini ${ }^{2}$, Vanessa Vinderfeltes Padilha ${ }^{1}$, \\ Brunno Zeni de Lima ${ }^{1}$
}

DOI: http:/ / dx.doi.org/10.1590/abd1806-4841.20187317

\begin{abstract}
Papular elastorrhexis is an acquired disease of elastic tissue; considered rare, its etiology and pathogenesis remain unknown. The vast majority of cases occur in women in the first or second decade of life. The disease manifests as multiple uniformly-sized, circumscribed, hypochromic and achromic papules located predominantly on the trunk and upper extremities. The lesions are generally asymptomatic and have a stable evolution over years. Its diagnosis is based on clinical and histopathological findings. The benignity of papular elastorrhexis and the subtlety of its clinical changes make the expectant treatment perfectly viable. The authors present one case in a young female patient.
\end{abstract}

Keywords: Dermis; Diagnosis, differential; Elastic tissue; Rare diseases

\section{INTRODUCTION}

Papular elastorrhexis is a disease of elastic tissue; considered rare, its etiology and pathogenesis remain unknown. Most cases occur in females in the first or second decade of life. There is usually no history of trauma, inflammation or previous acne. The disease is characterized by multiple small, uniformly-sized, circumscribed, hypochromic and achromic, non-follicular, oval or round papules located predominantly on the torso and upper extremities.

\section{CASE REPORT}

A 25-year-old white, female patient A 25-year-old white, female patient complained of lesions on the anterior side of the thorax and on the upper portion of the back, which emerged approximately seven years prior to the appointment, during pregnancy, and was accompanied by mild pruritus, pain and erythema. She was a smoker, $\mathrm{G}_{1} \mathrm{P}_{1} \mathrm{~A}_{0^{\prime}}$ and was using only oral contraception. There was no family history of dermatological affections or neoplasias.

During physical examination, papule-type lesions of whitish and yellowish coloration were noted on the anterior side of the thorax and on the upper part of the back (Figures 1 and 2). Grade 1 acne was also observed on the face. Steatocystoma multiplex and post-acne scarring were hypothesized, and a punch biopsy was performed.

The histopathological examination revealed an area of the skin with thickening of the dermal connective bundles, and Weigert's stain showed elastic fibers to be thin, fragmented and in reduced number in the examined topography, supporting the hypothesis of an elastic tissue disease such as papular elastorrhexis (Figure 3).

The patient was informed regarding the benignity of the condition. The proposed treatment was $2 \%$ triamcinolone infiltration on the lesions and, in refractory cases, an oral isotretinoin prescription.

\section{DISCUSSION}

Received 02 June 2017.

Accepted 20 November 2017.

* Work conducted at the Dermatology Service of the Hospital Universitário Evangélico de Curitiba, da Faculdade Evangélica do Paraná, Curitiba (PR), Brazil. Financial support: None.

Conflict of interests: None.

1 Dermatology Service, Hospital Universitário Evangélico de Curitiba, Faculdade Evangélica do Paraná, Curitiba (PR), Brazil.

2 Clinical Medicine Service, Fundação Hospitalar Santa Terezinha, Erechim (RS), Brazil.

MAILING AdDRess:

Layla Comel Corso Perito de Bem

E-mail: laylaccorso@gmail.com

C2018 by Anais Brasileiros de Dermatologia 
Papular elastorrhexis is an elastic tissue disease that is considered rare and whose etiology and pathogenesis remain unknown. ${ }^{1,2}$ The majority of cases occur in females in the first or second decade of life, in an episodic and acquired manner..$^{1,2}$ Rarely, an association with atopic dermatitis is observed. ${ }^{3}$ There is usually no history of trauma, inflammation or previous acne. ${ }^{1,4}$

The disease is characterized by multiple small, circumscribed, uniformly-sized, hypochromic and achromic, non-follicular, oval or rounded papules located predominantly on the torso and upper extremities. ${ }^{1,2,5}$ Rarely, there is involvement of the mandibular, occipitocervical and retroauricular regions, face and scalp. ${ }^{3}$ The lesions are generally asymptomatic, with a stable evolution over years. ${ }^{1}$ No extracutaneous manifestations have been reported. ${ }^{1}$

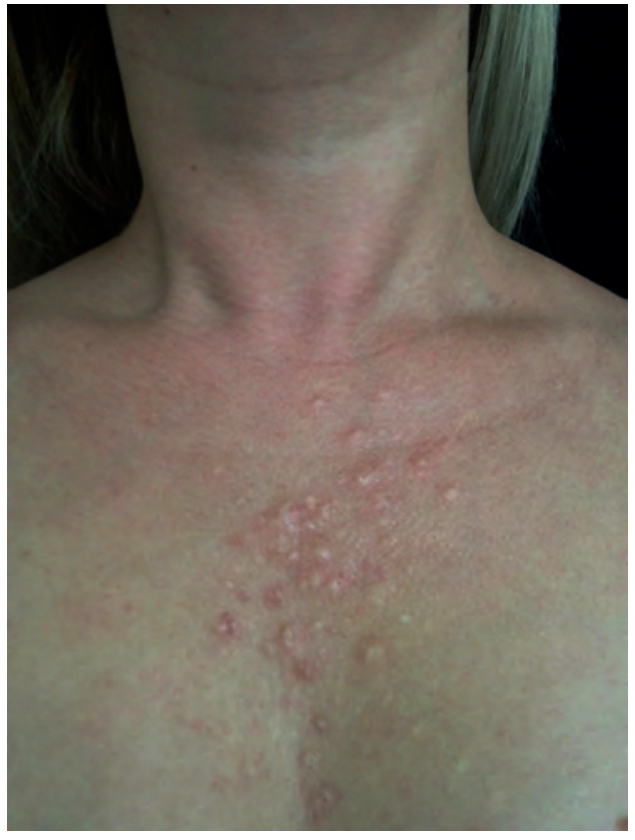

Figure 1:

Normochromic and confluent papules on the anterior side of the thorax

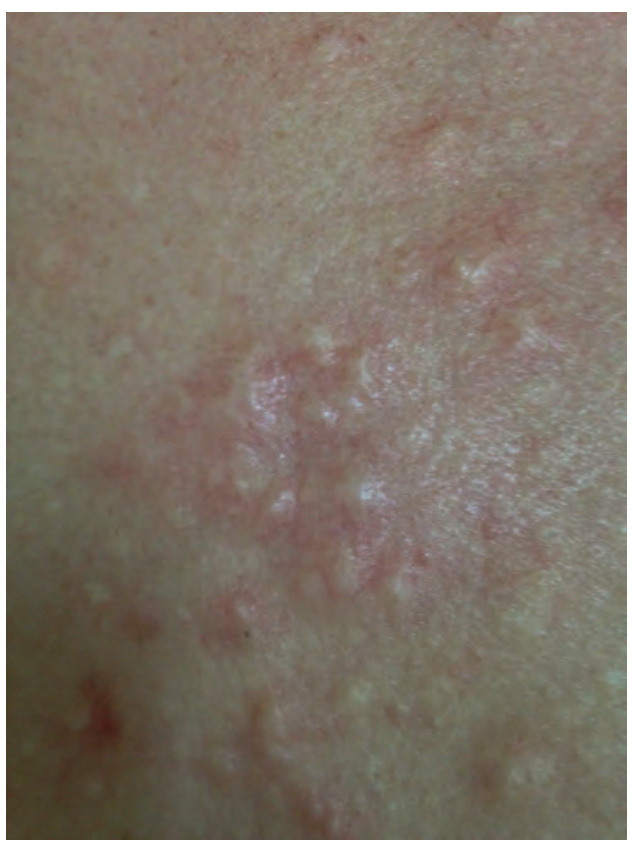

Figure 2: Normochromic confluent papules with erythematous borders
The diagnosis of papular elastorrhexis is based on clinical and histopathological findings. ${ }^{6}$ The histopathological assessment of the lesions reveals characteristic rarefaction and important fragmentation of the elastic fibers of the reticular dermis. ${ }^{4,5}$ There can be a perivascular lympho-histiocytic infiltrate. The collagen is thickened or normal. ${ }^{1,3}$ The presence of mucin should be evaluated during the histopathological examination to exclude associated diseases, such as lymphoma. ${ }^{1}$

Papular elastorrhexis was previously postulated to be a variant of nevus anelasticus or an abortive form of Buschke-Ollendorff syndrome. ${ }^{1}$ Currently, however, most authors agree that the disease is an entity distinct from the other. ${ }^{3}$ Nevus anelasticus is a predominantly congenital condition characterized by asymmetric, grouped, perifollicular papules on the anterior region of the thorax. ${ }^{5}$ The most important histopathological finding is a considerable reduction in the number of elastic fibers; in papular elastorrhexis, the fragmentation of such fibers is more characteristic. ${ }^{3}$

Buschke-Ollendorff syndrome is a dominant autosomal disease characterized by disseminated connective tissue nevi, associated with osteopoikilosis (disseminated condensing osteopathy). ${ }^{5}$ Elastomas are more commonly found in this syndrome, and the histopathology reveals an accumulation of elastic fibers, forming clusters. ${ }^{4,5}$ Papular elastorrhexis, however, differs from Buschke-Ollendorff syndrome in that it does not present hereditary characteristics, having a later onset, and does not present signs of osteopoikilosis. ${ }^{4}$

In addition to nevus anelasticus and Buschke-Ollendorff, the differential diagnosis includes eruptive collagenoma, papular acne scars, anetoderma, mid-dermal elastolysis, disseminated lenticular dermatofibrosis, postinflammatory elastolysis, pseudoxanthoma elasticum, and cutis laxa.

Eruptive collagenoma is an acquired disease that manifests in youth and is characterized by the presence of connective tissue nevi. ${ }^{7}$ The histopathology reveals an abnormal accumulation of components of the extracellular matrix (collagen, elastic fibers and glycosaminoglycans). ${ }^{7}$

Papular acne scars are, obviously, associated with a history

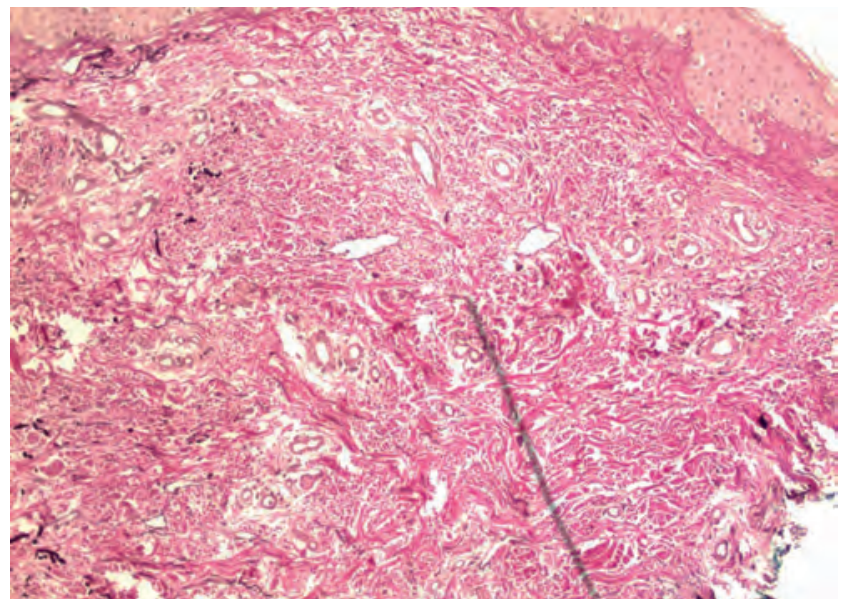

FIGURE 3: Areas with thickening of dermal connective bundles and reduced number of elastic fibers, which are thin and fragmented (Weigert, x20) 
of acne and do not occur in areas such as the abdomen and thighs. ${ }^{7}$ In anetoderma and mid-dermal elastolysis, elastolysis occurs in the absence of elastorrhexis, and the collagen is usually normal. ${ }^{7}$

Currently, there is no specific treatment for papular elastor- rhexis. ${ }^{3}$ Being a benign disease with only cosmetic complications, expectant management is acceptable. ${ }^{3}$ Some therapeutic options include oral antibiotics, oral isotretinoin, topical isotretinoin, benzoyl peroxide, and intralesional injection of triamcinolone; however, the response is variable and generally absent..$^{1,3,4}$

\section{REFERENCES}

1. Thomé EP, Steglich RB, Meotti CD, Schwartz J, Boff AL. Case for diagnosis. Papular elastorrhexis. An Bras Dermatol. 2012 Jul-Aug;87(4):651-3.

2. Sahin S, Durmaz EÖ, Sezer E, Cetin ED. Eruptive papular elastorrhexis of the face and scalp. J Am Acad Dermatol. 2013;69:e251-2.

3. Luo DQ, Liu JH, Chen MC, Wang Z, Xie WL. Papular elastorrhexis: report of four cases and review of literature. Arch Dermatol Res. 2015;307:99-108.

4. Emre S, Metin A, Demir-Pektaş S, Kılıçarslan A. Papular Elastorrhexis. Cutis. 2013:92:E4-5

\section{AUTHORS CONTRIBUTION \\ Layla Comel Corso Perito de Bem \\ (iD) ORCID 0000-0002-5398-9962 \\ Approval of the final version of the manuscript; Conception and planning of the study; Elaboration and writing of the manuscript; Obtaining, analyzing and interpreting the data; Critical review of the literature; Critical review of the manuscript \\ Alessandra Coppini \\ (iD) ORCID 0000-0002-5450-4859 \\ Elaboration and writing of the manuscript; Obtaining, analyzing and interpreting the data; Critical review of the manuscript}

5. Flores PB, Cuevas J, Sánchez C, De Eusebio E, Vergara A. Papular elastorrhexis: na acquired disorder of elastic tissue. Eur J Dermatol. 2010;20:525-6.

6. Chu DH, Goldbach H, Wanat KA, Rubin Al, Yan AC, Treat JR. A new variant of connective tissue nevus with elastorrhexis and predilection for the upper chest Pediatr Dermatol. 2015;32:518-21.

7. Kuwatsuka S, Kuwatsuka Y, Tomimura S, Utani A. Proposal of the new name "eruptive popular collageno-elastopathy" to unify the two indistinguishable entities eruptive collagenoma and popular elastorrhexis. J Dermatol. 2015;42:440-1.

How to cite this article: Bem LCCP, Coppini A, Padilha VV, Lima BZ. Papular elastorrhexis: a rare and benign disease. An Bras Dermatol. 2018;93(4):573-5. 